\title{
PETROGÊNESE DOS METABASITOS COM AFINIDADES DOS TOLEÍTOS DE FUNDO OCEÂNICO DAS REGIÕES DE ADRIANÓPOLIS E CAMPO LARGO/PR
}

\author{
VANDERLEI MANIESI $^{1}$ \& MARCOS AURÉLIO FARIAS DE OLIVEIRA ${ }^{2}$
}

\begin{abstract}
PETROGENESIS OF METABASALTS WITH OCEAN FLOOR THOLEIITES AFFINITY FROM THE ADRIANÓPOLIS AND CAMPO LARGO REGIONS, PARANÁ STATE The studied metabasites are orthoderived rocks associated with Proterozoic metasediments in the Açungui (Adrianópolis region) and Setuva (Campo Largo region) groups, State of Paraná. In the Adrianópolis region they present a tholeiitic character and affinities with enriched middle oceanic ridge basalts or, to a less extent, with oceanic islands. Their protoliths present little or moderate influence of fractional crystallization processes. The Campo Largo amphibolites represent a tholeiitic suite with high magnesium and transitional middle oceanic ridge basalts affinity. The geochemical characteristics of the amphibolites of the two studied regions indicate that the generation of their respective protoliths is related to a back arc basin as suggested by the country rocks environment and regional context (Açungui and Setuva basins).
\end{abstract}

Keywords: metabasites, petrogenesis, oceanic tholeiitic basalts, Açungui Group, Setuva Group.

RESUMO Os corpos de metabasitos estudados são constituídos por rochas ortoderivadas e estão inseridos em rochas metassedimentares preter proterom metabasitos com caráter toleítico e afinidades com os basaltos enriquecidos de cadeia meso oceânica, tendendo para ilha oceânica. ocorrem metabasitos com caráter toleiítico e afinidades com os basaltos enriquecidos de cadela meso oceânica, tendendo para ilha oceânica. que derivam de toleiitos de alto magnésio com afinidades com basaltos transicionais de cadeia meso oceânica. As rochas ígneas originais ti veram pouca a moderada influência da cristalização fracionada. As características geoquímicas dos metabasitos das duas regiões indican a possibilidade de seus protólitos estarem relacionados a bacias do tipo retro arco, tal como é sugerido para os ambientes de formação dos litotipos encaixantes regionais (bacias Açungui e Setuva).

Palavras-chave: metabasitos, petrogênese, basaltos toleiíticos oceânicos, Grupo Açungui, Grupo Setuva.

INTRODUÇÃo O Précambriano do estado do Paraná e sul de São Paulo contem diversas ocorrências de metabasitos, com alguns dados químicos divulgados, por exemplo, por Ebert (1987), Andrade e Silva (1990), Frascá et al. (1990), Campanha (1991), Reis Neto (1994) e Daitx (1996), indicando a presença de metabasitos ortoderivados com afinidades toleiíticas.

Os metabasitos localizados nos municípios de Adrianópolis e Campo Largo (Fig. 1), ocorrem em ambientes geológicos diferentes (grupos Açungui e Setuva), dentro da faixa de dobramentos Apiaí de Hasui et al. (1975) e Hasui et al. (1980). O presente trabalho visa um melhor conhecimento das manifestações básicas dessas duas localidades com relação à geologia, caracterização geoquímica, natureza de seus respectivos protólitos e possíveis processos petrogenéticos a que foram submetidos, como parte de projeto maior que envolve um amplo estudo de rochas metabásicas e metabasitos de parte das regiões sul e sudeste do Brasil, coordenada por um dos autores (M. A. F. de Oliveira).

Grupo Setuva. Soares (1987) reconheceu cinco associações metassedimentares e metavulcano-sedimentares para o Grupo Setuva, sendo (a) uma derivada de arenitos litorâneos gradando para pelitos plataformais; $(b, c)$ duas associações carbonáticas ricas em manganês desenvolvidas em plataforma profunda; (d) uma associação metavulcano-sedimentar com tufos, vulcânicas andesíticas a basálticas, calcários impuros, e camadas de metacherts ferríferos a manganesíferos; e (e) uma associações terrígena imatura correspondente a uma sequeencia retrogradacional de arenitos de leques submarinos, gradando para turbiditos. Soares (1987) utiliza o termo Complexo para o Grupo Setuva, do mesmo modo que Hasui et al. (1984), devido à intensa tectônica de lenticularização, dobramentos deitados e reempilhamento que afetou essas rochas.

A disposição dessas associações, de acordo com Soares (1987; 1988), bem como a intrusão de gabros e manifestações vulcânicas, teria ocorrido entre 1400 e 1220 ma. Supõem, ainda, para o Grupo Setuva, uma bacia tipo retro arco ativa no Proterozóico Médio, e posteriormente deformada por colisão arco/continente. Dessa forma, a primeira deformação e metamorfismo encontradas nos litotipos do Grupo Setuva, pertenceria ao final do Proterozóico Médio.

As rochas dessa unidade foram submetidas a um processo de dobramento isoclinal fechado com transposição dos planos (Pontes 1982; Fritzsons Júnior et al. 1982), relacionado a um cisalhamento dúctil de baixo ângulo (Soares 1987). O processo desenvolveu-se em condições termodinâmicas nas zonas da biotita e granada até estaurolita, de acordo com paragêneses minerais determinadas por Piekarz (1981), Pontes (1982), JICA/MMAJ (1984) e Reis Neto \& Soares (1987).

Grupo Açungui Soares (1987) utilizou o termo "Complexo" para as rochas do Grupo Açungui, no mesmo sentido que para as rochas do



Figura I - Mapa de localizaşão.

Grupo Setuva. É constituído por várias associações com empilhamento tectônico, ocorrendo em três sinclinórios: Capiru, Votuverava e Itaiacoca. Para este autor as rochas do Complexo Votuverava - Capiru - Itaiacoca, desenvolveram-se numa margem continental aquecida, após o resfriamento subsequente à colisão arco-continente que deformou o Grupo Setuva. Ocorrem metarenitos, metapelitos, metaritmitos, metacalcários e metadolomitos originários de diversos sistemas deposicionais como fluviais, litorâneos, de plataforma carbonática e de plataforma terrígena, entre outros.

A principal característica dessas rochas é a intensa deformação por cisalhamento rúptil-dúctil, de baixo ângulo, com intenso transporte ao longo dos planos. O fenômeno lenticularizou e re-empilhou as unidades num sistema de cavalgamento (Soares 1987, Fiori 1985, 1987, 1993), associado a metamorfismo na fácies xisto verde nas zonas da clorita e início da biotita. Para Soares (1987) esta tectônica teria transporte para sudeste, resultado da colisão continente - arco - continente no Proterozóico Superior.

1 Bolsista de Pós Doutorado da FAPESP, IG-USP/IGCE-UNESP, Av. 24A, 1515, Caixa Postal 178, CEP 13500-970, Rio Claro, SP

2 Instituto de Geociências e Ciências Exatas - UNESP, Av. 24A, 1515, Caixa Postal 178, CEP 13500-970, Rio Claro, SP 
Na região do Vale do Ribeira, envolvendo parte dos estados do Paraná e São Paulo, JICA/MMAJ (1981, 1982, 1983) dividem o Grupo Açungui em três formações denominadas da base para o topo de formacões I, II e III. Daitx et al. (1983) admitem as seguintes correlações: Formação Açungui I corresponde à Seqüencia Perau, Formação Açungui II corresponde total ou parcialmente à Formação Votuverava e a Formação Açungui III corresponde na sua quase totalidade à Formação Votuverava.

\section{GEOLOGIA E PETROGRAFIA A região de Adrianópolis}

A fígura 2 mostra a situação geológica da região de Adrianópolis, apresentando corpos de metabasitos alongados segundo a direção geral EW e NE-SW, inseridos nas rochas metassedimentares proterozóicas dos membros Superior e Intermediário da Formação Açungui III de JICA/MMAJ 1982 (Grupo Açungui). Afloram, ainda, nas proximidades, rochas do Complexo Granítico Três Córregos e do Granito Itaoca.

As rochas metassedimentares encaixantes dos metabasitos de Adrianópolis indicam que o metamorfismo atingiu a pressão e temperatura da fácies xisto verde, zona da biotita e zona da granada, de acordo com as seguintes associações: carbonato + quartzo + biotita; e clorita + biotita + sericita \pm granada \pm turmalina.

O corpo maior possui área aflorante de aproximadamente $3 \mathrm{~km}^{2}$, e espessura, em planta, que varia de 100 a 500 metros. Exibe contato litológico concordante e brusco com mármores calcíticos e cálcio xistos em sua porção norte e tectônico com a Falha Quarenta Oitava em sua porção sudoeste, bem como mica xistos em contato litológico a sudeste. Logo a sul desse corpo ocorrem dois corpos menores, parcialmente preservados do metamorfismo, com área inferior a $1 \mathrm{~km}^{2}$.

São metabasitos de coloração verde escura a cinza esverdeada escura e anisotropia predominantemente fraca, porém ocorrem litotipos com anisotropia forte e outros raros isotrópicos. As texturas presentes são granoblástica, poiquiloblástica e ofítica reliquiar, sendo que suas granulações variam de fina a fina-média e, esporadicamente, grossa, apresentando, de uma forma geral, tamanho médio dos cristais em torno de 6 milímetros e, embora raro, chega a 12 milímetros, dando à rocha um aspecto gabróico. Porém, de uma forma geral, possuem granulação entre 0,5 a 4 milímetros.

As rochas possuem como constituinte principal o anfibólio (51 a $66 \%$ ), com predomínio da hornblenda em relação à actinolita, ocorrendo tanto em cristais de composição homogênea quanto coexistindo as duas fases minerais dentro de um mesmo cristal, como manchas e/ou zoneamento composicional (Maniesi et al. 1996, Maniesi 1997). Além do anfibólio ocorrem também o plagioclásio (13 a $22 \%$ ) principalmente oligoclásio, albita e rara andesina; quartzo (7 a 15\%), epídoto (traços a $11 \%)$, biotita (0 a $8 \%)$, clorita $(0$ a $8 \%)$, granada ( $2 \%$ na amos- tra AD-15), carbonato (0 a 6\%), titanita (0 a 4\%), opacos (traços a 7\%) e ainda traços de apatita e, às vezes, traços de sericita e hematita/ goethita.

A região de Campo Largo Os metabasitos de Campo Largo (Fig. 3) estão alojados em rochas metassedimentares proterozóicas pertencentes à Formação Água Clara (Grupo Setuva), estando em parte em contato tectônico com as rochas metassedimentares da Formação Votuverava (Grupo Açungui). Afloram, ainda, nas proximidades dos metabasitos, rochas do Granito Passa Três e diques de diabásio mesozóicos.

A Formação Votuverava é representada na região de Campo Largo por filitos e metassiltitos, sendo identificadas estruturas primárias, como microestratificação cruzada, preservadas. O metamorfismo a que essas rochas foram submetidas foi da fácies xisto verde, zona da clorita e início da zona da biotita. Por outro lado, as rochas da Formação Água Clara são constituídas por cálcio xistos com quantidades variadas de carbonatos e tremolita-actinolita, granada - muscovita/biotita quartzo xistos com intercalação de quartzo xistos, quartzitos micáceos, xistos carbonosos, sericita plagioclásio xistos e quartzo-clorita xistos e também rochas calcissilicáticas (Soares \& Góis 1987, Piekarz 1992). As condições metamórficas para essas rochas são da fácies xisto verde, zona da biotita e granada, com retrometamorfismo na zona da clorita e biotita.

Os metabasitos de Campo Largo afloram em duas porções, configurando faixas alongadas segundo a direção geral NE/SW, com uma área de pouco mais de $4 \mathrm{~km}^{2}$ (Fig. 3). São rochas de coloração cinza escura, esverdeada escura e, mais raro, cinza clara esverdeada. Possuem anisotropia moderada a fraca e tamanho dos cristais predominando entre 1 e 4 milímetros.

A textura granoblástica é a feição textural predominante em função do arranjo em mosaico granular de quartzo, plagioclásio e, às vezes, de epídoto, sendo também comumente encontradas feições ígneas reliquiares, semelhantes à textura ofítica.

A mineralogia principal é representada por anfibólio ( 45 a $65 \%$ ), predominando as variedades de actinolita em relação às de hornblenda, exibindo cristais composicionalmente homogêneos e também outros manchados e/ou zonados (Maniesi et al. 1996, Maniesi 1997); plagioclásio (11 a 27\%), representado por albita e raro oligoclásio; quartzo (4 a $12 \%$ ), epídoto (traços a $16 \%$ ), opacos (traços a $4 \%$ ), biotita (0 a $6 \%)$, clorita (traços a $7 \%)$, carbonato (0 a $9 \%$ ), titanita (0 a $4 \%$ ), além de traços de apatita, sericita, turmalina e hematita/goethita.

GEOQUímICA Os dados químicos dos metabasitos das regiões de Adrianópolis e Campo Largo (Tabs. 1 e 2), foram obtidos a partir da
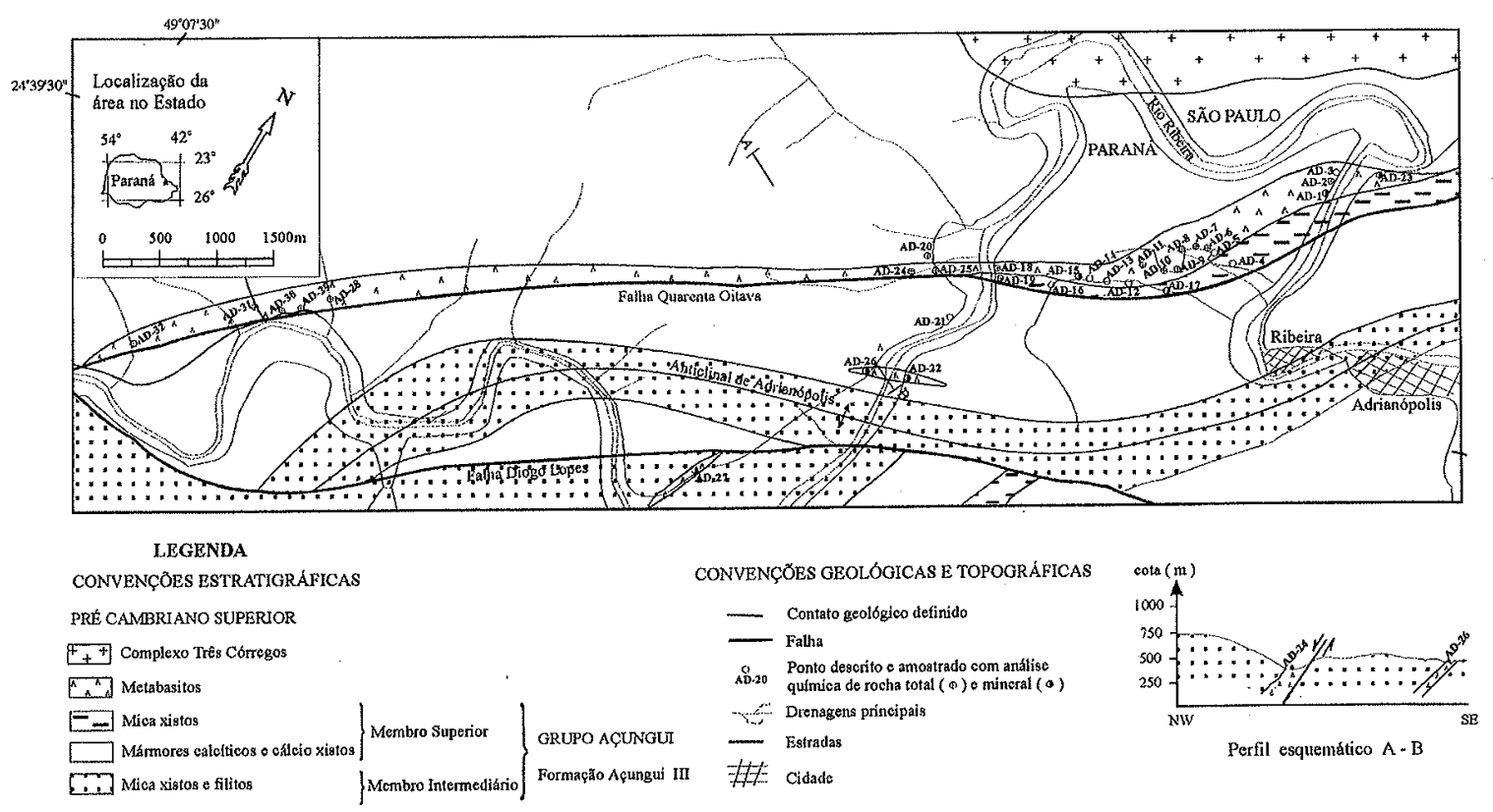


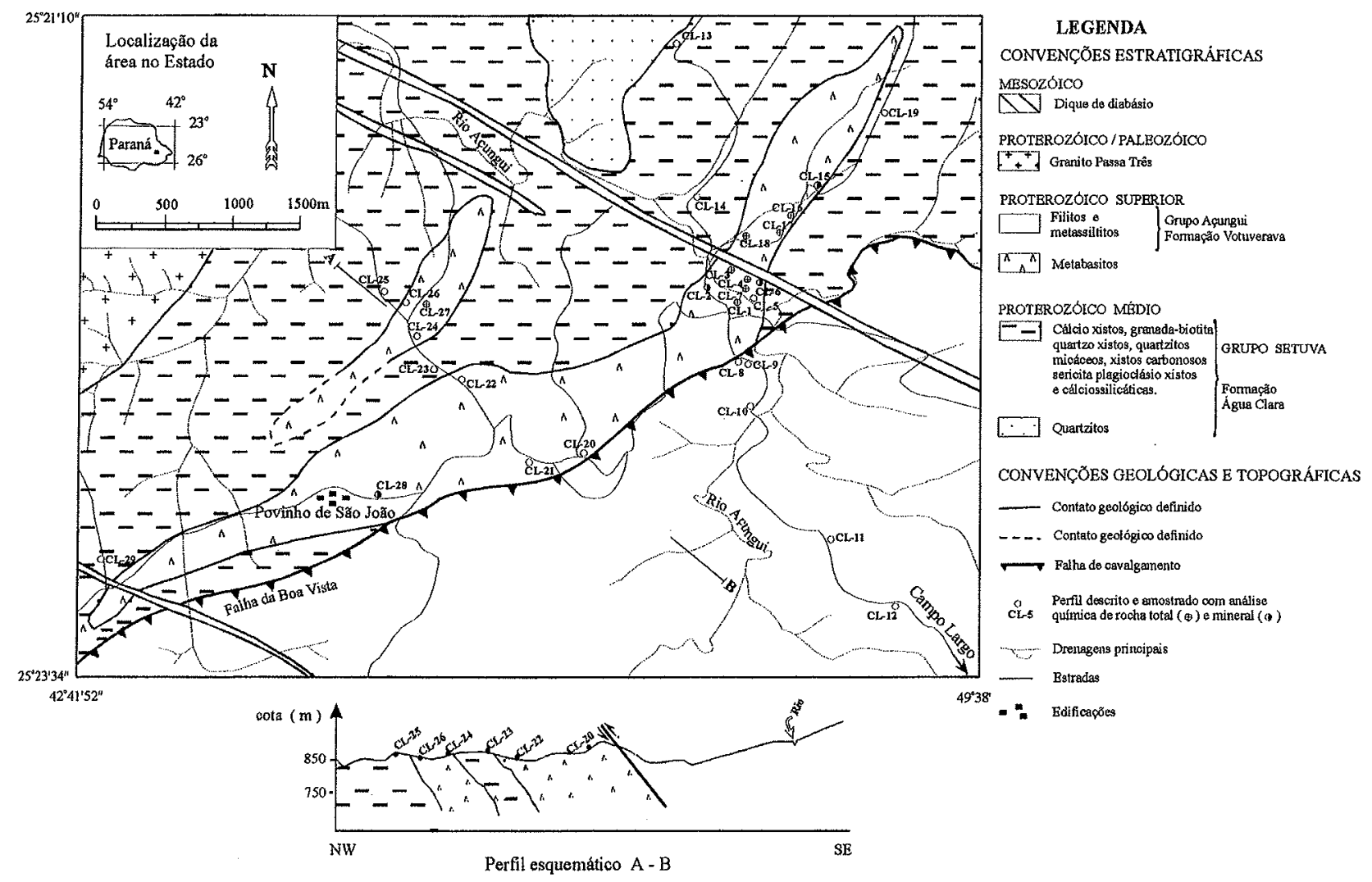

Figura 3 - Mapa geológico da região de Campo Largo (modificado de Andrade et al. 1990, Katbeh et al. 1990 e Piekarz. 1992).

seleção de 40 amostras para dosagem dos seguintes elementos: $\mathrm{SiO}_{\text {, }}$ $\mathrm{TiO}_{2}, \mathrm{Al}_{2} \mathrm{O}_{3}, \mathrm{Fe}_{2} \mathrm{O}_{3}, \mathrm{FeO}, \mathrm{MnO}, \mathrm{MgO}, \mathrm{CaO}, \mathrm{Na}_{2} \mathrm{O}, \mathrm{K}, \mathrm{O}, \mathrm{P}_{2} \mathrm{O}_{5}, \mathrm{Cr}$, $\mathrm{Ni}, \hat{R}_{\mathrm{b}}, \mathrm{S}^{2} \mathrm{Z}, \mathrm{Zr}$ e Y por fluorescência de Raios X (LABOGEO-ÚNESP' Rio Claro). Dessas amostras, 24 pertencem aos metabasitos da região de Adrianópolis e 16 aos de Campo Largo. Para um melhor detalhamento químico, selecionaram-se também 9 amostras para dosagem dos conteúdos de $\mathrm{Nb}$ e elementos terras raras $(\mathrm{La}, \mathrm{Ce}, \mathrm{Nd}, \mathrm{Sm}$, $\mathrm{Eu}, \mathrm{Gd}, \mathrm{Dy}, \mathrm{Ho}, \mathrm{Er}, \mathrm{Yb}$ e Lu) por ICP-AES; LABOGEO-UNESP/Rio Claro, e 14 para Hf, Ta, U e Th por ICP-MS (Laboratório Activation Ltd - Canadá).

A análise conjunta dos teores dos elementos químicos (Tabs. 1 e 2), permite a individualização de dois agrupamentos geoquímicos distintos, representados, respectivamente, pelos metabasitos de Adrianópolis e Campo Largo. Os agrupamentos revelam diferenças em praticamente todos os elementos químicos analisados, principalmente nos conteúdos de $\mathrm{TiO}_{2}, \mathrm{P}_{2} \mathrm{O}_{5}, \mathrm{MgO}, \mathrm{Zr}, \mathrm{Hf}, \mathrm{Nb}, \mathrm{Ta}$, Th, $\mathrm{U}$ e elementos terras raras, como consta da Tabela 3.

A natureza ortoderivada Os metabasitos das duas regióes estudadas mostram texturas ígneas ainda preservadas da deformação $\mathrm{e}$ metamorfismo a que foram submetidas. São feições caracterizadas pela presença de tramas entre cristais de plagioclásio e anfibólio, sugerindo texturas reliquiares semelhantes à ofítica, sub-ofítica e intergranular.

Com relação aos dados químicos, a natureza ortoderivada dos metabasitos foi testada utilizando os diagramas da Fig. 4. No diagrama de Leake (1964), Fig. 4A, são confrontados os parâmetros de Niggli mg e $c$ (Niggli 1954), exibindo os campos dos pelitos e calcários, bem como linhas composicionais para misturas pelitocalcário, pelito-dolomito e linha de tendência de diferenciação dos doleritos do Karroo. O diagrama revela que os metabasitos estudados, principalmente os de Adrianópolis, aproximam-se da tendência composicional dos doleritos do Karroo.

O diagrama $\mathrm{Zr} / \mathrm{TiO}_{2}$ vs. Ni (Fig. 4B) de Winchester et al. (1980) sugere uma origem ígnea para esses metabasitos, exceto para 3 amostras que se posicionam no campo de rochas sedimentares, embora estando próximas à linha que limita os campos de rochas ígneas e sedimentares.

Possíveis alterações pós magmáticas Os metabasitos de Adrianópolis e Campo Largo, tiveram no transcorrer de suas histórias
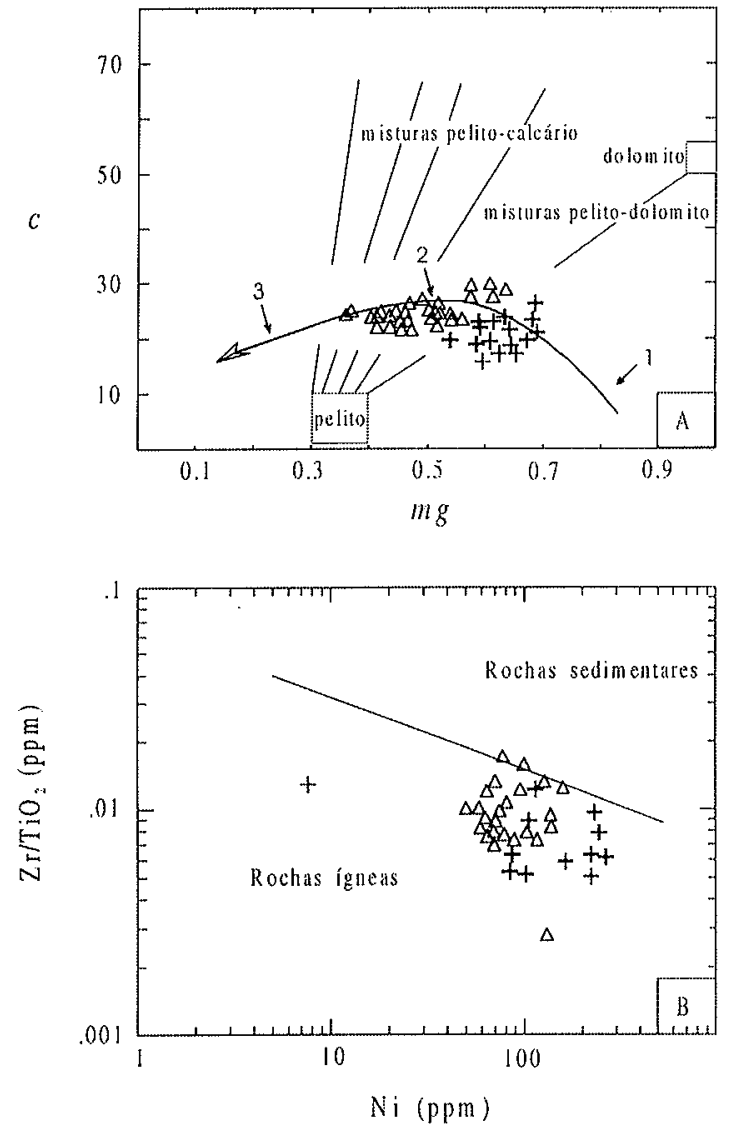

Figura 4 - Diagramas A (Leake 1964) e B (Winchester et al. 1980) para a caracterização química da origem dos protólitos dos metabasitos de Adrianópolis (triângulos) e Campo Largo (cruzes). 1, 2 e 3 correspondem respectivamente aos estágios de diferenciação iniciais ou cumulatos, intermediários e finais dos doleritos do Karroo. 
Tabela l- Teores dos elementos maiores, menores (\%) e traços (ppm) dos metabasitos de Adrianópolis (AD-) e Campo Largo (CL-). Para o cálculo das composições normativas e dos valores de ing\# foi utilizada a razão $\mathrm{Fe}_{2} \mathrm{O}_{3} / \mathrm{FeO}=0,15$.

\begin{tabular}{|c|c|c|c|c|c|c|c|c|c|c|c|c|c|c|c|c|c|c|c|}
\hline & $A D-1$ & AD-1.1 & $A D-I C$ & AD-2 & AD-6 & AD-7A & $\overline{\mathrm{AD}}-8 \mathrm{~A}$ & AD-9 & $A D-10$ & $A D-11$ & AD-23.1 & AD-23.2 & $\mathrm{AD}-23.3$ & AD-23A & $\mathrm{AD}-23 \mathrm{E}$ & AD-23F & AD-24.3 & AD-28.2 & AD-29 \\
\hline $\mathrm{SiO}_{2}$ & 50.22 & 49.73 & 49.28 & 50.01 & 49.44 & 48.97 & 48.30 & 49.54 & 49.52 & 49.80 & 50.04 & 49.33 & $48.9 \mathrm{l}$ & 48.52 & 49.60 & 42.20 & 48.34 & 47.12 & 48.17 \\
\hline $\mathrm{TiO}_{2}$ & 1.46 & 1.57 & 1.88 & 1.30 & 1.46 & 1.26 & 1.63 & 1.67 & 1.73 & 1.38 & 1.57 & 1.25 & 1.36 & 2.15 & 1.77 & 2.24 & 1.29 & 1.31 & 1.44 \\
\hline $\mathrm{Al}_{2} \mathrm{O}_{3}$ & 12.93 & 12.72 & 12.69 & 14.62 & 13.36 & 14.17 & 12.47 & 12.97 & 12.41 & 13.21 & 12.94 & 15.03 & 13.62 & 11.96 & 13.57 & 12.73 & 13.63 & 13.91 & 12.54 \\
\hline $\mathrm{Fe}_{2} \mathrm{O}_{3}$ & 4.69 & 3.89 & 4.18 & 3.92 & 4.00 & 2.74 & 2.98 & 3.40 & 4.27 & 4.25 & 5.97 & 4.36 & 4.90 & 6.50 & 6.46 & 10.07 & 6.28 & 3.76 & 4.95 \\
\hline $\mathrm{FeO}$ & 9.12 & 9.78 & 10.69 & 8.36 & 9.88 & 8.77 & 10.52 & 10.14 & 10.10 & 8.55 & 8.20 & 7.48 & 8.00 & 9.50 & 7.73 & 9.44 & $6.50)$ & 8.84 & 8.10 \\
\hline $\mathrm{MnO}$ & 0.21 & 0.21 & 0.21 & 0.19 & 0.20 & 0.17 & 0.20 & 0.20 & 0.21 & 0.19 & 0.22 & 0.19 & 0.20 & 0.24 & 0.21 & 0.26 & 0.20 & 0.22 & 0.23 \\
\hline $\mathrm{MgO}$ & 6.05 & 6.20 & 5.95 & 6.10 & 6.28 & 7.91 & 6.45 & 6.44 & 6.41 & 7.52 & 5.72 & 6.18 & 7.83 & 5.91 & 5.92 & 5.82 & 7.51 & 7.64 & 8.02 \\
\hline $\mathrm{CaO}$ & 9.22 & 9.27 & 8.98 & 9.99 & 9.13 & 9.42 & 9,06 & 8.62 & 8.56 & 8.94 & 9.22 & 10.38 & 10.05 & 9.06 & 8.40 & 10.24 & 9.48 & 10.28 & 9.66 \\
\hline $\mathrm{Na} 2 \mathrm{O}$ & 2.59 & 2.89 & 2.49 & 2.24 & 2.67 & 2.82 & 3.41 & 3.12 & 2.94 & 2.38 & 2.73 & 2.62 & 1.97 & 2.54 & 2.61 & 2.06 & 2.39 & 2.17 & 2.15 \\
\hline $\mathrm{K}_{2} \mathrm{O}$ & 0.27 & 0.25 & 0.43 & 0.26 & 0.20 & 0.14 & 0.55 & 0.25 & 0.24 & 0.15 & 0.42 & 0.31 & 0.25 & 0.39 & 0.82 & 0.33 & 0.22 & 0.40 & 0.41 \\
\hline $\mathrm{P}_{2} \mathrm{O}_{3}$ & 0.24 & 0.20 & 0.22 & 0.17 & 0.19 & 0.17 & 0.22 & 0.23 & 0.23 & 0.15 & 0.21 & 0.17 & 0.19 & 0.22 & 0.25 & 0.35 & 0.17 & 0.19 & 0.18 \\
\hline P.F. & 1.99 & 2.21 & 1.80 & 1.93 & 2.14 & 2.48 & 3.05 & 2.29 & 2.25 & 2.54 & 1.83 & 1.87 & 1.84 & 1.93 & 1.80 & 3.23 & 3.26 & 3.19 & 3.25 \\
\hline rolal & 98.99 & 98.92 & 98.80 & $99 .(1)$ & 98.95 & 99.02 & 98.84 & 98.87 & 98.87 & 99.06 & 99.07 & 99.17 & 99.12 & 98.92 & 99.14 & 98.97 & 99.27 & 99.03 & 99.10 \\
\hline & 0.45 & 0.45 & 0.42 & 0.48 & 0.45 & 0.56 & 0.47 & 0.47 & 0.45 & 0.52 & 0.4 .3 & 0.49 & 0.53 & 0.41 & 0.44 & 0.36 & 0.52 & 0.53 & 0.53 \\
\hline \multicolumn{20}{|c|}{ Composiçào normaliva } \\
\hline Q & 5.67 & 2.82 & 4,04 & 5.44 & 3.28 & 0.00 & 0.00 & 1.35 & 3.06 & 4.75 & 6.11 & 2.85 & 4.37 & 5.62 & 5.96 & 1.86 & 4.63 & $0.00)$ & 2.96 \\
\hline Opx & 17.34 & 18.38 & 17.96 & 17.74 & 20. 26 & 21.45 & 8.67 & 21,09 & 20.01 & 21.71 & 13.22 & 15.12 & 20.07 & 14.39 & 14.37 & $11 .(x)$ & 16.04 & 17.11 & 19.60 \\
\hline$C p x$ & 17.41 & 19.43 & 17.24 & $15.80)$ & 16.57 & 16.30 & 21.77 & 14.93 & 17.21 & 14.97 & 18.31 & 17.89 & 16.97 & 19.07 & 13.79 & 19.30 & 16.02 & 13.87 & 18.78 \\
\hline ol & 0.00 & 0.00 & 0.00 & 0.00 & 0.00 & 1.71 & 8.21 & $0,00)$ & $0.01)$ & 0.00 & 0.00 & 0.00 & 0.00 & $0,00)$ & 0.00 & 0.00 & 0.00 & 0.00 & 0.00 \\
\hline \multicolumn{20}{|l|}{ Traços } \\
\hline $\begin{array}{l}\mathrm{Ni} \\
\mathrm{Cr}\end{array}$ & $\begin{array}{l}62 \\
25\end{array}$ & $\begin{array}{l}61 \\
80\end{array}$ & $\begin{array}{l}67 \\
99\end{array}$ & $\begin{array}{l}67 \\
92\end{array}$ & $\begin{array}{c}65 \\
1(14\end{array}$ & $\begin{array}{l}102 \\
150\end{array}$ & 72 & $\begin{array}{l}65 \\
89\end{array}$ & $\begin{array}{l}67 \\
79\end{array}$ & $\begin{array}{l}69 \\
99\end{array}$ & $\begin{array}{l}79 \\
13\end{array}$ & $\begin{array}{l}126 \\
112\end{array}$ & 213 & 78 & 66 & 119 & 61 & 160 & $\begin{array}{l}144 \\
178\end{array}$ \\
\hline $\mathrm{Sr}$ & 237 & 180 & $\begin{array}{c}99 \\
237\end{array}$ & $\begin{array}{l}92 \\
3(x)\end{array}$ & $\begin{array}{l}104 \\
366\end{array}$ & $\begin{array}{l}150 \\
238\end{array}$ & $\begin{array}{c}93 \\
205\end{array}$ & 242 & 166 & 231 & 335 & 301 & 250 & 211 & 157 & 177 & 293 & 332 & 193 \\
\hline $\mathrm{Rb}$ & 7 & 8 & 6 & 9 & 5 & 8 & 30 & 5 & 4 & 5 & 15 & 10) & 7 & 14 & 38 & 7 & 10 & 14 & 15 \\
\hline $\mathrm{Zr}$ & 71 & 79 & 231 & 101 & 118 & 67 & 140 & 152 & 154 & 49 & 165 & 165 & 171 & 277 & 294 & 408 & 164 & 113 & 72 \\
\hline$Y$ & 22 & 25 & 19 & 15 & 16 & 17 & 21 & 16 & 19 & 18 & 15 & 12 & 14 & 15 & 19 & 21 & 13 & 14 & 16 \\
\hline $\mathrm{Ba}$ & 506 & 204 & 142 & 434 & 144 & 337 & 328 & 212 & 139 & 138 & 110 & 544 & 260 & 160 & 250 & 65 & 72 & 204 & 160 \\
\hline $\mathrm{Nb}$ & 17 & 19 & $\cdot$ & - & - & 14 & - & - & . & 14 & . & 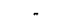 & - & - & & - & & - & 14 \\
\hline $\mathrm{HF}$ & 3.18 & 3.49 & - & . & - & 2.39 & - & - & - & 2.47 & - & - & - & - & - & $\therefore$ & - & - & 2.51 \\
\hline $\mathrm{Ta}$ & 0.81 & 1.01 & - & . & . & 0.66 & - & - & - & 0.64 & - & - & - & - & & - & 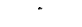 & - & 0.69 \\
\hline Th & 2.01 & 2.28 & . & - & • & 1.20 & - & - & - & 1.65 & - & - & - & - & - & - & - & : & $\begin{array}{l}1.62 \\
0.79\end{array}$ \\
\hline U & 0.41 & 0.41 & & 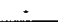 & - & (0.51 & & 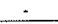 & $\therefore$ & 0.34 & & $\therefore$ & - & & & - & - & 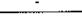 & 0.29 \\
\hline
\end{tabular}

\begin{tabular}{|c|c|c|c|c|c|c|c|c|c|c|c|c|c|c|c|c|c|c|}
\hline & AD-30 & AD-31. & AD-31.3 & AD-32.2 & CL-3.2 & $\mathrm{CL} \cdot \mathbf{3 . 3}$ & CL-3.5 & $\mathrm{CL}-4$ & $\mathrm{CL}-6$ & CL-7 & CL-15A & CL-15B & $\mathrm{CL}-15 \mathrm{C}$ & $\mathrm{CL}+16$ & $\mathrm{CL}-17$ & CL-18 & CL-27 & CL-28 \\
\hline $\mathrm{SiO}_{2}$ & 47.18 & 47.79 & 48.92 & 48.16 & 43.49 & 45.23 & 43.33 & 46.81 & 44.60 & 48.81 & 48.65 & 49.46 & 51.87 & 47.91 & 46.32 & 47.77 & 50.06 & 47.67 \\
\hline $\mathrm{TO}_{3}$ & 1.36 & 1.37 & 1.54 & 1.93 & 0.59 & 0.70 & 0.59 & 0.80 & 0.86 & 0.73 & 0.67 & 0.70 & 0.70 & 0.99 & 0.79 & 0.72 & 0.89 & 0.61 \\
\hline $\mathrm{Al}_{2} \mathrm{O}_{3}$ & 14.80 & 12.97 & 13.27 & 12.42 & 11.35 & 13.40 & 14.17 & 13.92 & 14.86 & 11.60 & 1.6 .86 & 13.89 & 12.86 & 12.94 & 12.03 & 14.13 & 11.41 & 10.89 \\
\hline $\mathrm{Fc}_{2} \mathrm{O}_{3}$ & 4.90 & 4.55 & 4.81 & 8.54 & 3.96 & 4.19 & 2.28 & 3.92 & 5.96 & 5.02 & 2.67 & 4.28 & 2.55 & 5.13 & 4.13 & 5.77 & 4.17 & 5.19 \\
\hline $\mathrm{FeO}$ & 7.65 & 8.57 & 7.74 & 8.62 & 7.19 & 6.50 & 8.44 & 8.45 & 8.73 & 7.77 & 7.87 & 7.82 & 8.21 & 8.20 & 9.41 & 5.73 & 6.82 & 5.79 \\
\hline $\mathrm{MnO}$ & 0.21 & 0.23 & 0.22 & 0.26 & 0.23 & 0.21 & 0.19 & 0.19 & 0.23 & 0.23 & 0.19 & 0.26 & 0.23 & 0.26 & 0.22 & 0.19 & 0.21 & 0.19 \\
\hline $\mathrm{MgO}$ & 7.14 & 8.20 & 6.85 & 5.00 & 13.15 & 13.22 & 12.89 & 11.02 & 9.39 & $\mathbf{1 0 . 2 9}$ & 9.08 & 9.69 & 9.57 & 10.04 & 10.93 & 9.65 & 10.32 & 12.85 \\
\hline $\mathrm{CaO}$ & 9.18 & 9.34 & 9.69 & 8.75 & 11.00 & 9.58 & 9.11 & 7.44 & 8.34 & 9.42 & 5.47 & 6.11 & 6.48 & 7.65 & 10.27 & 9.61 & 10.10 & 12.05 \\
\hline $\mathrm{Na} \mathrm{a}_{2} \mathrm{O}$ & 2.74 & 2.26 & 2.16 & 2.07 & 2.19 & 2.25 & 2.57 & 3.23 & 2.03 & 2.01 & 3.82 & 3.38 & 3.56 & 2.71 & 1.91 & 2.09 & 2.94 & $1 .(0)$ \\
\hline $\mathrm{K}_{2} \mathrm{O}$ & 0.46 & 0.40 & 0.21 & 0.34 & 0.10 & 0.23 & 0.13 & 0.24 & 0.21 & 0.26 & 0.10 & 0.09 & 0.09 & 0.13 & 0.14 & 1.13 & 0.30 & 0.09 \\
\hline $\mathrm{P}_{2} \mathrm{O}_{3}$ & 0.18 & 0.18 & 0.16 & 0.28 & 0.06 & 0.06 & 0.07 & 0,09 & 0.06 & 0.05 & 0.05 & 0.04 & 0.07 & 0.08 & 0.08 & 0.06 & 0.10 & 0.05 \\
\hline P.F. & 3.34 & 3.19 & 3.58 & 2.67 & 5.80 & 3.72 & 5.30 & 2.95 & 3.75 & 2.94 & 3.75 & 3.41 & 2.91 & 3.06 & 2.75 & 2.51 & 1.93 & 2.98 \\
\hline Total & 99.15 & 98.05 & 99.15 & 99.04 & 99.20 & 99.29 & 99.07 & 99.06 & 99.03 & 99.13 & 99.13 & 99.13 & 99.10 & 99.10 & 98.98 & 99.36 & 99.24 & 99.36 \\
\hline & 0.51 & 0.54 & 0.50 & 0.35 & 0.69 & 0.69 & 0.69 & 0.62 & 0.54 & 0.60 & 0.61 & 0.60 & 0.62 & 0.58 & 0.60 & 0.61 & 0.63 & 0.69 \\
\hline \multicolumn{19}{|c|}{ Composiçăo normativa } \\
\hline$Q$ & 0.00 & 1.31 & 5.88 & 10.50 & 0.00 & 0,00 & 0.00 & 0.00 & 0.00 & 1.78 & 0.00 & 0.00 & 0.06 & 0.00 & 0.00 & 0.00 & 0.00 & 1.53 \\
\hline Opx & 18.17 & 22,08 & 16.85 & 11.47 & 0.00 & 5.59 & 0.00 & 7.49 & 21.82 & 25.47 & 8.21 & 27.73 & 30.98 & 26.39 & 16.88 & 16.93 & 15.71 & 24.66 \\
\hline$C p x$ & 14.21 & 10.90 & 17.02 & 14.53 & 26.97 & 16.97 & 14.48 & 10.89 & 8.24 & 19.68 & 0.00 & 6.08 & $\mathbf{I}(0,39$ & 11.78 & 21.49 & $17.00)$ & 25.94 & 27.24 \\
\hline of & 0.62 & 0.00 & 0.00 & 0.00 & 20.96 & 19.25 & 27.49 & 18.73 & 5.55 & 0.00 & 11.02 & 2,46 & 0.00 & 1.86 & 9.35 & 2.81 & 4.00 & $0.04)$ \\
\hline \multicolumn{19}{|c|}{ Traços } \\
\hline $\mathrm{Ni}$ & 112 & 145 & 88 & 74 & 226 & $2(x)$ & 214 & 157 & 103 & 7 & 79) & 85 & 108 & $\begin{array}{l}1.13 \\
140\end{array}$ & $\begin{array}{l}233 \\
342\end{array}$ & 224 & 267 & $\begin{array}{l}294 \\
654\end{array}$ \\
\hline $\mathrm{C}_{r}$ & 139 & 172 & 84 & 45 & 536 & 618 & 565 & 418 & 150) & 161 & 52 & 99 & $\begin{array}{l}158 \\
45\end{array}$ & $\begin{array}{l}140 \\
92\end{array}$ & $\begin{array}{l}342 \\
160\end{array}$ & $\begin{array}{l}224 \\
193\end{array}$ & 99 & $\begin{array}{l}0.34 \\
231\end{array}$ \\
\hline $\begin{array}{l}\mathrm{Sr} \\
\mathrm{Rb}\end{array}$ & 295 & 184 & 314 & 142 & $1(x)$ & 225 & 248 & 99 & 180) & $\begin{array}{l}115 \\
12\end{array}$ & $\begin{array}{c}125 \\
8\end{array}$ & $\begin{array}{c}54 \\
6\end{array}$ & $\begin{array}{c}45 \\
7\end{array}$ & 6 & 6 & 50 & 12 & 5 \\
\hline $\mathrm{Rb}$ & $\begin{array}{c}14 \\
106\end{array}$ & $\begin{array}{l}11 \\
83\end{array}$ & 8 & 10 & 10) & $\begin{array}{c}9 \\
25\end{array}$ & $\begin{array}{c}7 \\
26\end{array}$ & $\begin{array}{l}16 \\
35\end{array}$ & $\begin{array}{l}10 \\
10\end{array}$ & $\begin{array}{l}12 \\
25\end{array}$ & $\begin{array}{c}8 \\
39\end{array}$ & 41 & 43 & 52 & 62 & 10 & 2 & 40 \\
\hline $\begin{array}{l}\mathrm{Zr} \\
\mathrm{Y}\end{array}$ & $\begin{array}{l}106 \\
13\end{array}$ & $\begin{array}{l}83 \\
18\end{array}$ & $\begin{array}{c}118 \\
12\end{array}$ & $\begin{array}{l}77 \\
19\end{array}$ & $\begin{array}{l}25 \\
10\end{array}$ & $\begin{array}{c}25 \\
9\end{array}$ & $\begin{array}{l}26 \\
10\end{array}$ & 14 & 12 & 14 & Ii) & 10 & 12 & 15 & 15 & 13 & 11 & 10 \\
\hline $\begin{array}{l}Y \\
\mathrm{Ba}\end{array}$ & $\begin{array}{c}13 \\
193\end{array}$ & $\begin{array}{c}18 \\
177\end{array}$ & $\begin{array}{c}12 \\
118\end{array}$ & $\begin{array}{l}19 \\
75\end{array}$ & $\begin{array}{l}17 \\
188\end{array}$ & 483 & 216 & 214 & 182 & 107 & 87 & 28 & 56 & 166 & 60 & 528 & 189 & 58 \\
\hline $\mathrm{Nb}$ & . & 13 & - & 17 & - & 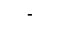 & 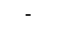 & 6.80 & - & 7.10 & - & 5.80 & 5.70 & $7.40)$ & 7.10 & - & . & 6.60 \\
\hline HI & . & 2.52 & - & 3.23 & - & - & - & 1.52 & - & 1.26 & - & 0.82 & 1.17 & 1.59 & 1.28 & - & - & $1.00)$ \\
\hline $\mathrm{Ta}$ & - & 0.70 & 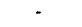 & 0.94 & - & - & - & 0.23 & - & 0.15 & - & 0.12 & 0.17 & 0.22 & 0.18 & - & - & 0.14 \\
\hline Th & - & 1.61 & - & 2,21 & - & - & - & 0.34 & - & 0.37 & - & 0.21 & 0.32 & 0.51 & 0.32 & . & - & 0.21 \\
\hline U & . & 0.29 & 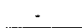 & 0.43 & . & - & - & 0.07 & & 0.08 & - & 0.04 & 0,06 & 0.10 & 0.07 & - & - & 0.03 \\
\hline
\end{tabular}

Tabela 2 - Teores dos elementos terras raras ( $\mathrm{ppm}$ ) e normalizados pelo condrito de Evensen et al. (1978) dos metabasitos de Adrianópolis (AD-) e Campo Largo ( $C L-)$.

\begin{tabular}{|c|c|c|c|c|c|c|c|c|c|}
\hline & AD-1 & $\mathrm{AD}-1 \mathrm{C}$ & AD-7A & AD-II & CL-7 & Cl.15C & Cl-16 & $\mathrm{Cl},-17$ & Cl-28 \\
\hline La & {$[9.59$} & 21.81 & 16.18 & 16.51 & 4.05 & 4.33 & 6.12 & 4.64 & 2.65 \\
\hline $\mathrm{cc}$ & 35.35 & 38.73 & 28.13 & 29.79 & 8.73 & 9.34 & 12.05 & 8.90 & 6.85 \\
\hline No & 21.61 & 23.42 & 16.88 & 17.91 & 6.64 & 6.99 & 8.98 & 7.78 & 5.54 \\
\hline $\mathrm{Sm}$ & 5.63 & 6.97 & 4.41 & 5.09 & 2.68 & 2.36 & 2.25 & 2.59 & 2.38 \\
\hline Eu & 1.61 & 1.96 & 1.29 & 1.39 & 0.94 & 0.75 & 1.02 & 0.45 & 0.77 \\
\hline Gd & 4.77 & 5,44 & 3.51 & 4.06 & 2.17 & 2.21 & 3.30 & 2.72 & 2.01 \\
\hline Dy & 4.55 & 4.83 & 3.17 & 3.55 & 2.26 & 2.38 & 3.31 & 2.85 & 2.08 \\
\hline Ho & 1.10 & 1.24 & 0.86 & 0.95 & 0.74 & 0.62 & 0.93 & 0.98 & 0.67 \\
\hline $\mathrm{Er}$ & 2.64 & 2.93 & 2.01 & 2.23 & 1.64 & 1.69 & 2.19 & 1.94 & 1.43 \\
\hline Yb & 2.40 & 2.32 & 1.81 & 1.91 & 1.40 & 1.33 & 1.82 & 1.16 & 1.11 \\
\hline Lu & 0.34 & 0.31 & 0.24 & 0.30 & 0.21 & 0.20 & 0.27 & 0.19 & 0.16 \\
\hline LaN & 80.09 & 89.17 & 66,15 & 67.50 & 16.56 & 17.70 & 25.02 & 18.97 & 10.83 \\
\hline $\mathrm{CcN}$ & 55.42 & 60.71 & 44.10 & 46.70 & 13.69 & 14.64 & 18.89 & 13.95 & 10.74 \\
\hline NuN & 45.61 & 49.43 & 35.63 & 37.80 & 14.01 & 14.75 & 18.95 & 16.42 & 11.69 \\
\hline $\operatorname{SinN}$ & 36.56 & 45.26 & 28.64 & 33.05 & 17.40 & 15.32 & 14.61 & 16.82 & 15.45 \\
\hline EuN & 27.76 & 33.79 & 22.24 & 23.97 & 16.21 & 12.93 & 17.59 & 16.38 & 13.28 \\
\hline GdN & 23.35 & 26.63 & 17.18 & 19.87 & 10.62 & 10.82 & 16.15 & 13.31 & 9.84 \\
\hline DyN & 17.90 & 19.00 & 12.47 & 13.97 & 8.89 & 9.36 & 13.02 & 11.21 & 8.18 \\
\hline $\mathrm{HoN}$ & 19.40 & 21.87 & 15.17 & 16.75 & 13.05 & 10.93 & 16.40 & 17.28 & 11.82 \\
\hline $\mathrm{ErN}$ & 15.89 & 17.64 & 12.10 & 13.43 & 9.87 & 10.17 & 13.18 & 11.68 & 8.61 \\
\hline YbN & 15.38 & 14.87 & 11.60 & 12.24 & 8.97 & 8.53 & 11.67 & 7.44 & 7.12 \\
\hline LuN & 13.39 & 12.20 & 9.45 & 11.81 & 8.27 & 7.87 & 10.63 & 7.48 & 6.30 \\
\hline$\Sigma$ ETRN & 350.75 & 390.58 & 274.72 & 297.09 & 137.55 & 133.04 & 176.12 & 150.94 & 113.86 \\
\hline$(\mathrm{Cd} / \mathrm{Sm}) \mathrm{N}$ & 1.52 & 1.34 & 1.54 & 1.41 & 0.79 & 0.46 & 1.29 & 0.83 & 0.69 \\
\hline$(\mathrm{Gd} / Y \mathrm{~b}) \mathrm{N}$ & 1.52 & 1.79 & 1.48 & 1.62 & 1.18 & 1.27 & 1.38 & 1.79 & 1.38 \\
\hline$(\mathrm{Ce} / \mathrm{Yb}) \mathrm{N}$ & 3.60 & 4.08 & 3.80 & 3.81 & 1.52 & 1.72 & 1.62 & 1.88 & 1.51 \\
\hline $\mathrm{Eu} / \mathrm{E} u^{*}$ & 0.95 & 0.97 & 1.00 & 0.94 & 1.19 & $1 .(0)$ & 1.14 & 1.09 & 1.08 \\
\hline
\end{tabular}

Tabela 3 - Diferenças composicionais entre os metabasitos de Adrianópolis e Campo Laigo.

\begin{tabular}{|c|c|c|}
\hline & Adrianópolis & Campo Largo \\
\hline $\mathrm{MgO}$ & 5,00 a $8,20 \%$ & 9,39 a $13,27 \%$ \\
\hline $\mathrm{TiO}_{2}$ & 1,25 a $2,24 \%$ & 0,59 a $1,00 \%$ \\
\hline $\mathrm{P}_{2} \mathrm{O}_{5}$ & 0,15 a $0,35 \%$ & 0,04 a $0,10 \%$ \\
\hline $\mathrm{Zr}$ & 49 a $408 \mathrm{ppm}$ & 2 a $63 \mathrm{ppm}$ \\
\hline $\mathrm{Hf}$ & 2,39 a $3,49 \mathrm{ppm}$ & 0,82 a $1,59 \mathrm{ppm}$ \\
\hline $\mathrm{Nb}$ & 13 a $19 \mathrm{ppm}$ & 5,70 a $7,40 \mathrm{ppm}$ \\
\hline $\mathrm{Ta}$ & 0,70 a $1,01 \mathrm{ppm}$ & 0,12 a $0,23 \mathrm{ppm}$ \\
\hline $\mathrm{Th}$ & 1,20 a $2,28 \mathrm{ppm}$ & 0,21 a $0,51 \mathrm{ppm}$ \\
\hline $\mathrm{U}$ & 0,29 a $0,51 \mathrm{ppm}$ & 0,03 a $0,10 \mathrm{ppm}$ \\
\hline$\sum \mathrm{ETR}$ & 274,72 a 390,58 & 113,88 a 176,12 \\
\hline
\end{tabular}


geológicas, influências de processos pós magmáticos que poderiam mudar seu quimismo original.

Estudos realizados por Miyashiro (1975) mostram uma mobilidade relativamente intensa do $\mathrm{Na}_{2} \mathrm{O}$ e $\mathrm{K}_{2} \mathrm{O}$ e consequentemente também do $\mathrm{Rb}$ e $\mathrm{Cs}$, em rochas submetidas ao metamorfismo de baixo grau. $\mathrm{O}$ autor propõe o diagrama $\mathrm{Na}_{2} \mathrm{O}+\mathrm{K}_{2} \mathrm{O} v s . \log \mathrm{Na}_{2} \mathrm{O} / \mathrm{K}_{2} \mathrm{O}$ para a determinação de possíveis alterações pós magmáticas, baseando-se em rochas quaternárias frescas e alteradas pertencentes a diversos ambientes geotectônicos do planeta. A utilização do diagrama para os metabasitos estudados (Fig. 5) evidenciou que apenas 3 amostras localizam-se no campo de rochas alteradas.

Beswick \& Soucie (1978) propuseram, através de dados analíticos de uma suíte de rochas metavulcânicas, que podem ser testadas possíveis alterações no quimismo de protólitos ígneos por processos metamórficos e metassomáticos. São diagramas envolvendo razão de proporção molecular logarítmica a partir de porcentagens em peso de rocha total dos elementos $\mathrm{SiO}_{2}, \mathrm{~K}_{2} \mathrm{O}, \mathrm{CaO}, \mathrm{Al}_{2} \mathrm{O}_{3}$ e Fm $(\mathrm{FeO}+\mathrm{MnO}$ $+\mathrm{MgO}$ ), onde se observam as tendências evolutivas de rochas ígneas.

Com base nesse critério (Fig. 6), os metabasitos de Adrianópolis e Campo Largo apresentam uma coerência nos agrupamentos e tendên-

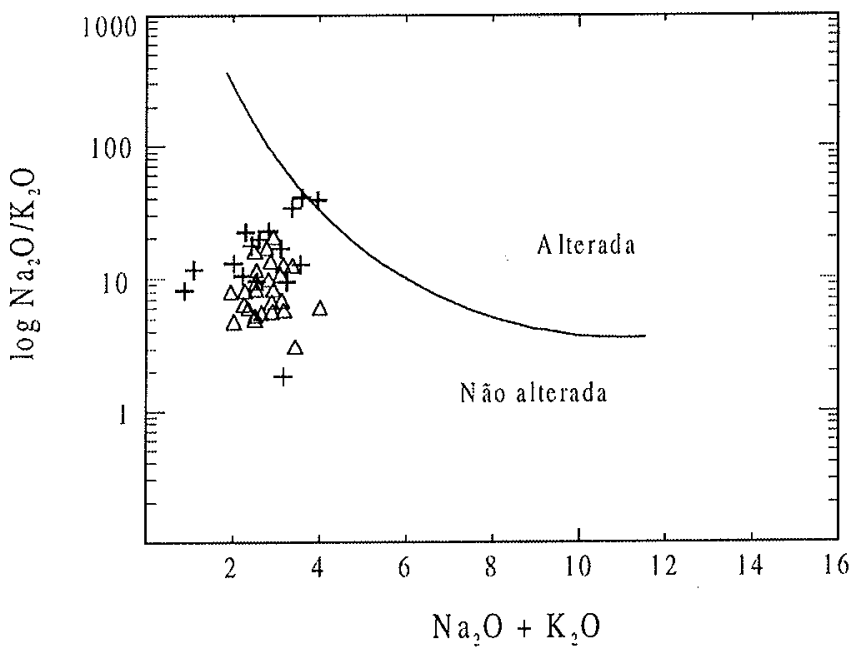

Figura 5 - Diagrama $\mathrm{Na}_{2} \mathrm{O}+\mathrm{K}_{2} \mathrm{O}$ vs. $\log \mathrm{Na}_{2} \mathrm{O} / \mathrm{K}_{2} \mathrm{O}$ proposto por Miyashiro (1975), discriminando os metabasitos de Adrianópolis (triângulos) e Campo Largo (cruzes) que sofreram alteração pós magmáticas nos conteúdos de sódio e potássio. cias nos diagramas de Beswick \& Soucie (1978), com dispersões mínimas ou desprezíveis, sugerindo que não devem ter sofrido modificações químicas pós magmáticas significativas. Com isso, o quimismo atual desses metabasitos reflete, com grande aproximação, o quimismo ígneo original.

Nomenclatura e classificação Em uma primeira análise dos dados químicos da Tabela 1, verifica-se em relação aos teores de $\mathrm{SiO}_{2}$ rochas de natureza básica $\left(45 \%<\mathrm{SiO}_{2}<53 \%\right.$ ), sendo encontradas, segundo o diagrama R1 vs. R2, (Fig. 7), principalmente composições de andesi basaltos e basaltos subalcalinos, tendo também com certa frequiência, composições dos basaltos transicionais nos metabasitos de Campo Largo. Composições de basaltos transicionais, mesmo que raras, também são encontradas entre os litotipos de Adrianópolis.

É caracterizada a afinidade toleítica dos metabasitos de Adrianópolis e Campo Largo pela baixa razão alcalis/sílica (Fig. 8), enriquecimento de $\mathrm{F}(\mathrm{FeO})$ em relação a $\mathrm{A}\left(\mathrm{Na}_{2} \mathrm{O}+\mathrm{K}_{2} \mathrm{O}\right)$ e $\mathrm{M}(\mathrm{MgO})$

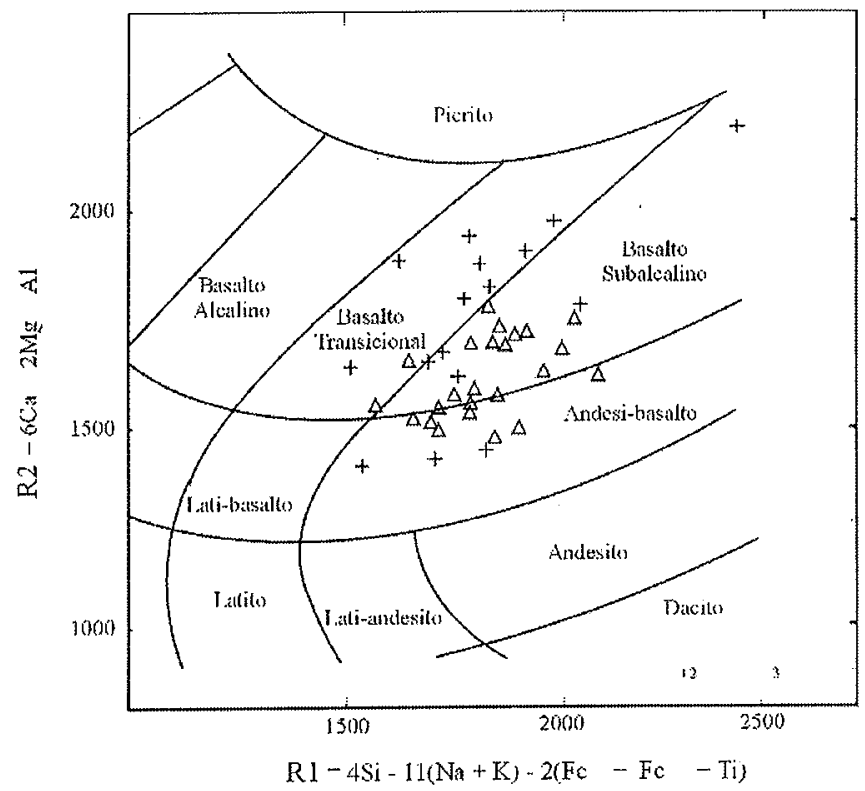

Figura 7 - Distribuição dos metabasitos de Adrianópolis (triângulos) e Campo Largo (cruzes) no diagrama de De La Roche et al. (1980).

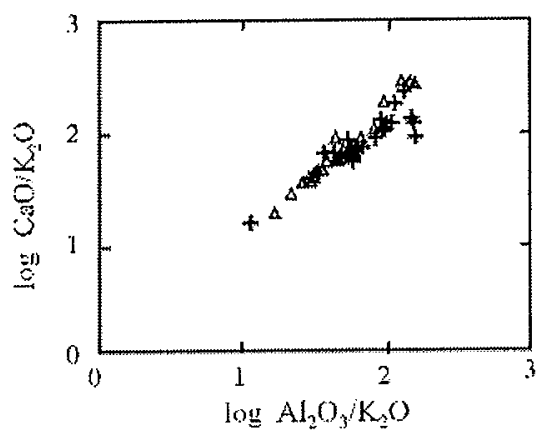


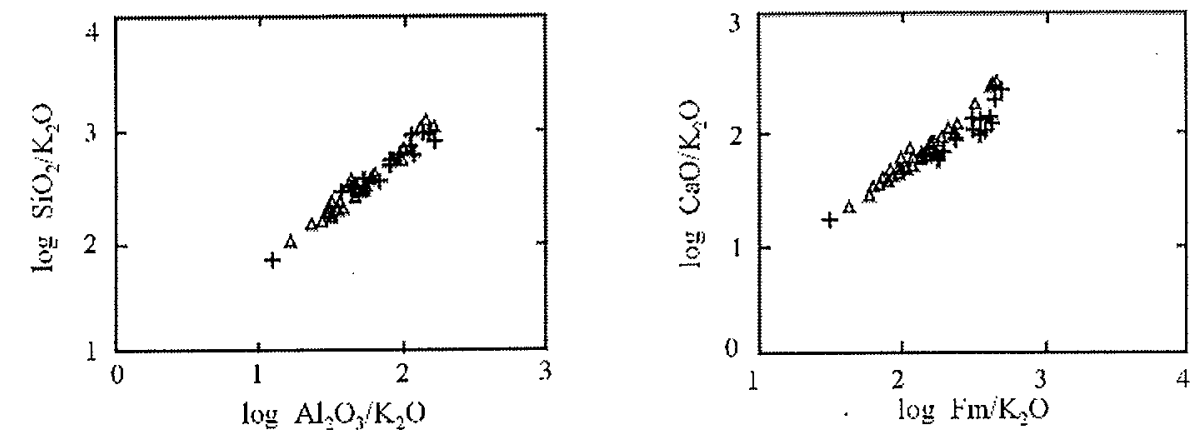

Figura 6 - Diagramas envolvendo razões de proporção molecular logarítmica (Beswick \& Soucie 1978) com os teores dos metabasitos de Adrianópolis (triangulos) e Campo Largo (cruzes). $\mathrm{Fm}=\mathrm{FeO}+\mathrm{MgO}+\mathrm{MnO}$. 


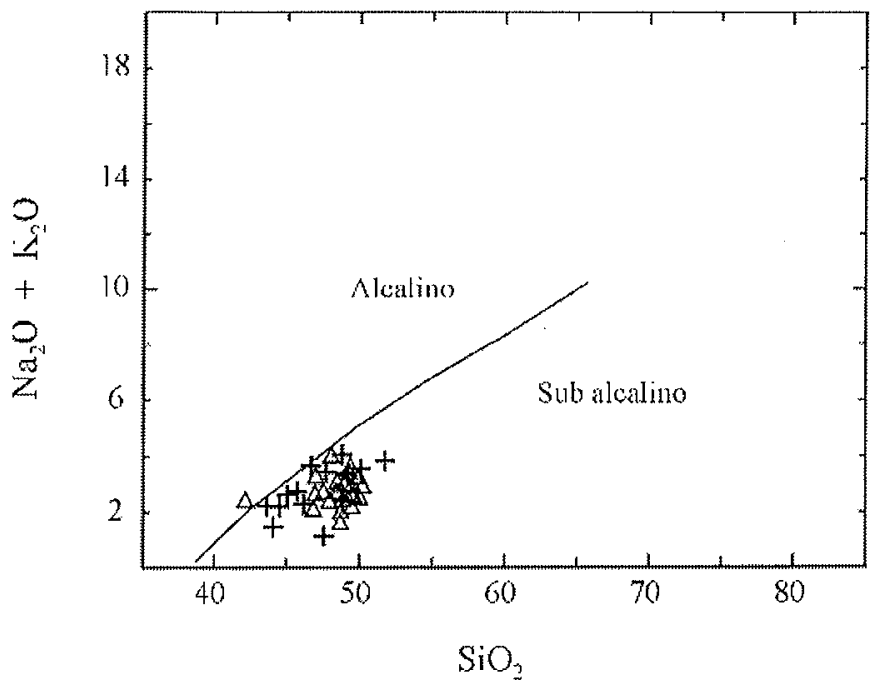

Figura 8 - Diagrana silica vs. alcalis (Irvine \& Baragar 1971) para os metabasitos de Adrianópolis (triângulos) e Campo Largo (cruzes).

no diagrama AFM (Fig. 9) e pela presença de olivina toleiitos e toleiitos supersaturados no diagrama normativo $\mathrm{Qz}-\mathrm{Opx}-\mathrm{Cpx}-\mathrm{Ol}-\mathrm{Ne}$ (Fig. 10). Os metabasitos de Adrianópolis destacam suas afinidades toleiíticas pelos critérios acima citados, além de apresentarem-se mais ricos em Fe, $\mathrm{P}, \mathrm{Sr}, \mathrm{Zr}, \mathrm{Nb}, \mathrm{Hf}$, Ta, U e Th.

$\mathrm{O}$ diagrama $\mathrm{Al}_{2} \mathrm{O}_{3}$ vs. $\mathrm{FeO}+\mathrm{TiO}_{2}$ vs. MgO de Jensen 1976 (Fig. 11) possibilita a dístinção entre a natureza toleiítica e komatítica de rochas máfico-ultramáficas. Entre os metabasitos estudados, os que possuem teores de $\mathrm{MgO}$ acima de $10 \%$ posicionam-se no campo dos basaltos komatiíticos. Os metabasitos de Adrianópolis apresentam composições predominantemente de Fe-toleiitos e de modo subordinado de Mg-toleiitos. Os metabasitos de Campo Largo estão nos campos dos $\mathrm{Mg}$-toleiitos e dos basaltos komatíticos.

PETROGÊNESE Os dados petrográficos e geoquímicos indicam que os metabasitos estudados tiveram suas origens a partir de protólitos ígneos toleiíticos sem ter passado por alterações pós magmáticas significativas.

Pearce et al. (1975) propuseram o diagrama $\mathrm{TiO}_{2}$ vs. $\mathrm{K}_{2} \mathrm{O} v s . \mathrm{P}_{2} \mathrm{O}_{5}$, mostrando a possibilidade de se distinguir basaltos oceânicos de continentais. O campo dos basaltos oceânicos inclui os basaltos de cadeia meso oceânica e de ilha oceânica e o campo dos basaltos continentais inclui os basaltos da província Karoo. Nesse diagrama os metabasitos de Adrianópolis e Campo Largo distribuem-se no campo dos basaltos oceânicos (Fig. 12).

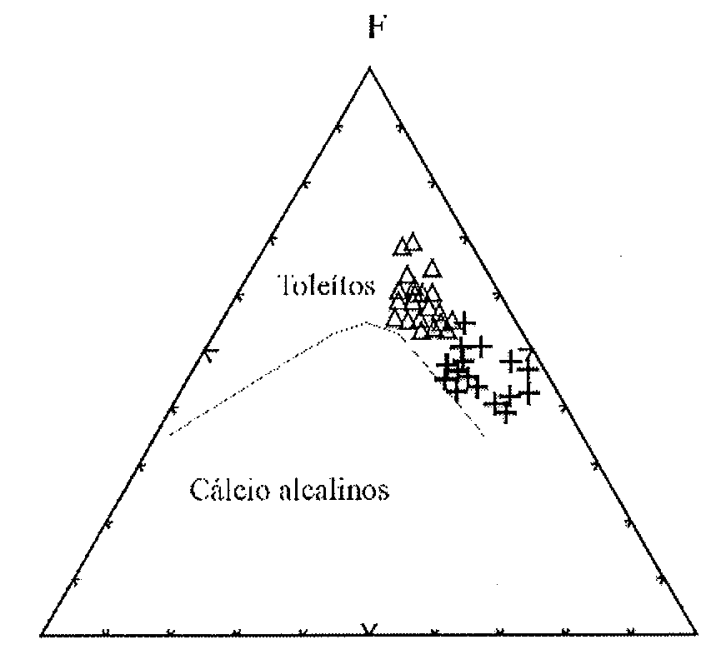

A

Figura 9-Diagrama AFM $\left(\mathrm{A}=\mathrm{Na}_{2} \mathrm{O}+\mathrm{K}_{2} \mathrm{O} ; \mathrm{F}=\mathrm{FeO} ; \mathrm{M}=\mathrm{MgO}\right)$ de Irvine \& Baragar (1971) para os metabasitos de Adrianópolis (triangulos) e Campo Largo (cruzes).

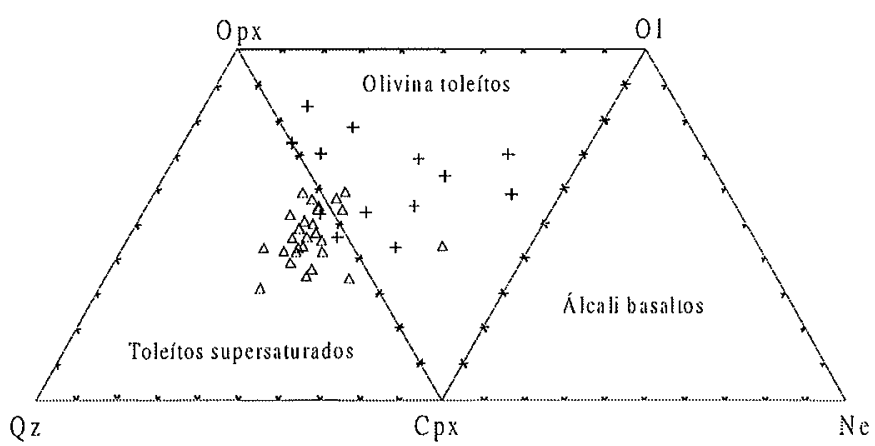

Figura 10 - Diagrana simplificado de composição mineralógica normativa projetado no sistema basaltico de Yoder \& Tilley (1962), con os dados dos metabasitos de Adrianópolis (triângulos) e Campo Largo (cruzes).

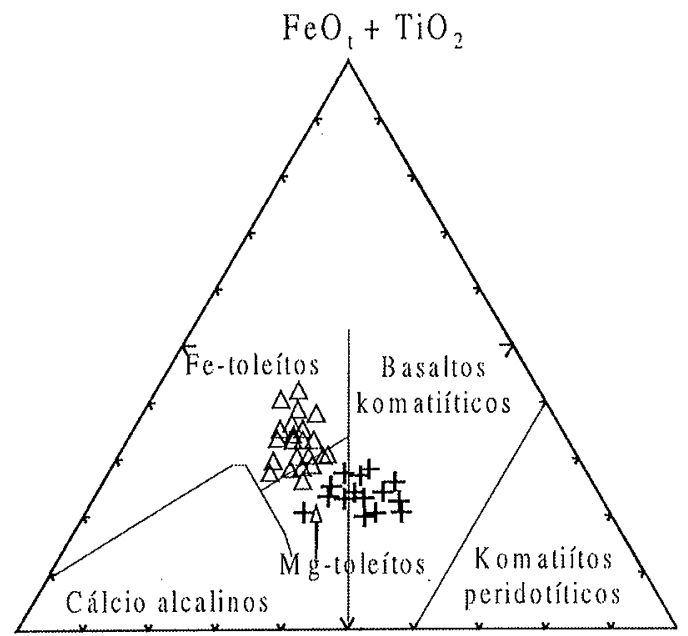

$\mathrm{Al}_{2} \mathrm{O}_{3} \quad \mathrm{MgO}$

Figura II-Diagrama $\mathrm{Al}_{2} \mathrm{O}_{3}$ vs. $\mathrm{FeO}_{1}+\mathrm{TiO}_{2}$ vs. $\mathrm{MgO}$ de Jensen (1976) para os metabasitos de Adrianópolis (triângulos) e Campo Largo (cruzes)

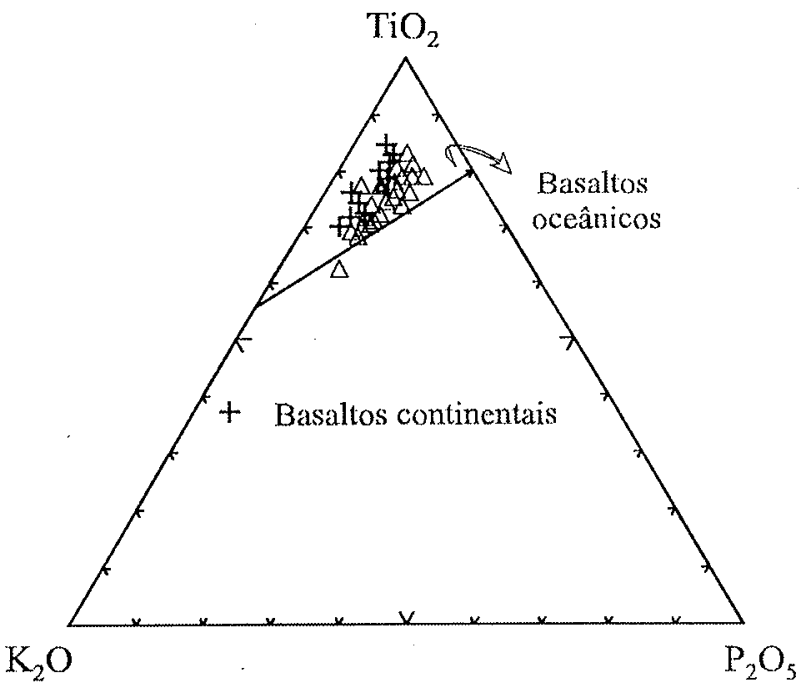

Figura 12 - Diagrama $\mathrm{K}_{2} \mathrm{O}$ vs. $\mathrm{TiO}_{2}$ vs. $\mathrm{P}_{2} \mathrm{O}_{5}$ de Pearce et al. (1975) distinguindo os cantpo de basaltos oceânicos e continentais com os teores dos metabasitos de Adrianópolis (triângulos) e Campo Largo (cruzes). 
Metabasitos de Adrianópolis São metabasitos que possuem padrōes de distribuição dos elementos incompatíveis mais enriquecidos que os basaltos E-MORB, tendendo para as composições dos basaltos de ilha oceânica (OIB), Fig. 13. A tendência para a composição de ilha oceânica é marcada pelo enriquecimento principalmente em Th, Ba e Rb, além de Sm, Hf, Nb, Ta e Th. Os conteúdos dos ETR são consistentes com as composições intermediárias entre os basaltos $\mathrm{E}$ MORB e de ilha oceânica, uma vez que apresentam inclinação em seus padrões de abundância $\left(\mathrm{Ce}_{\mathrm{N}} / \mathrm{Yb}_{\mathrm{N}}=3,60 \mathrm{a} 4,08\right)$ em função de seus enriquecimentos de ETRL em relação aos ETRP (Tab. 2 e Fig. 14). A pouca variação composicional entre seus litotipos $(\mathrm{MgO}=5,72$ a $8,20 \%$ e mg\# = 0,35 a 0,56, Tab. 1) sugere pouca a moderada influência da cristalização fracionada na geração dos litotipos ígneos originais.

Metabasitos de Campo Largo Comparando-se com os basaltos N-MORB, os metabasitos de Campo Largo apresentam maiores teores em $\mathrm{Rb}, \mathrm{Ba}$, Th e $\mathrm{Nb}$ e em algumas amostras verifica-se também enriquecimento em $\mathrm{Sr}$ (Fig. 13). Em relação aos metabasitos de Adrianópolis, os de Campo Largo possuem menores conteúdos de ETR $_{\text {NTOTAL }}(113,88$ a 176,12 vs. 274,72 a 390,58$)$ e padrões de abundância mais horizontalizados $\left(\mathrm{Ce}_{\mathrm{N}} / \mathrm{Yb}_{\mathrm{N}}=1,51\right.$ a 1,88 vs. 3,60 a 4,08, Tab. 2 e Fig. 14). Essas feições geoquímicas indicam que o protólito dos metabasitos de Campo Largo possuía composição semelhante aos basaltos transicionais de cadeia meso oceânica (T-MORB). O fracionamento magmático de seu protólito parece ter influenciado no surgimento das fracas anomalias de $\mathrm{Eu}(\mathrm{Eu} / \mathrm{Eu} *$ até 1,19$)$, estando possivelmente relacionadas à quantidade de líquido magmático em equilíbrio com o plagioclásio.

Tal como ocorre para os metabasitos de Adrianópolis a pouca variação composicional dos litotipos de Campo Largo $(\mathrm{MgO}=9,08$ a $13,27 \%$ e mg\# $=0,54$ a 0,69 , Tab. 1) revela que seu protólito ígneo deve ter tido pouca a moderada influência do processo de cristalização fracionada na evolução magmática, originando composições dos basaltos komatíticos como os termos mais primitivos, possivelmente ricos em clinopiroxênio e também em plagioclásio, e os termos mais evoluídos mostrando composições dos $\mathrm{Mg}$-toleiitos. Os dados geoquímicos exibidos neste trabalho, juntamente com as diferentes


Figura 13 - Padrões de distribuição de elementos incompatíveis nommalizados pelo N-MORB de Pearce (1983) para os metabasitos de Adrianópolis e Campo Largo. linhas de tendências evolutivas nos diagramas de variação química (Maniesi 1997), sugerem que o protólito de Campo Largo foi gerado em maior grau de fusão parcial em relação ao líquido inicial do protólito dos metabasitos de Adrianópolis, a partir de diferentes fontes mantélicas.

CONCLUSÕES Os metabasitos das regiões de Adrianópolis e Campo Largo são rochas ortoderivadas, possivelmente de caráter intrusivo, relacionadas a magmatismo basáltico toleiítico que faz parte da história da evolução geológica respectivamente das bacias Açungui e Setuva em tempos proterozóicos. Possuem composição química dos basaltos oceânicos e seus protólitos ígneos foram gerados a partir de fontes mantélicas composicionalmente diferentes, com grau de fusão parcial menor para os metabasitos de Adrianópolis quando comparados com os metabasitos de Campo Largo e tiveram pouca a moderada influência do processo de cristalização fracionada na evolução magmática de seus respectivos protólitos.

Quanto ao ambiente geotectônico em que foram gerados os metabasitos das regiões estudadas, os dados permitem excluir os ambientes continental (basaltos toleíticos continentais) e de zona de colisão (basaltos cálcio alcalinos). Mantém-se, portanto, a possibilidade dos protólitos dos metabasitos das regiōes de Adrianópolis e Campo Largo, terem sido gerados em ambientes de bacia de retro arco em concordância com o que é proposto para os contextos regionais onde estão inseridos, ou seja, as bacias Setuva (Soares 1987) e Açungui (Soares 1987, Fiori 1990).

De um modo geral é aceito que as bacias retro arco são distensionais, geradas por processos tipo espalhamento de fundo oceânico semelhantes às cadeias meso oceânicas (e.g. Sauder's \& Tarney 1979. Crawfort et al. 1981, Taylor \& Karner 1983, Jarrard 1986). No entanto, são mencionadas diferenças nos processos de geração de magmas entre os clois ambientes em relação à composição da fonte, profundidade, graus de fusão parcial e também a participação de componentes derivados da placa subductante, dependendo da geometria do arco.

Esses fatores podem afetar o processo de geração de magmas, produzindo basaltos com características geoquímicas transicionais ou
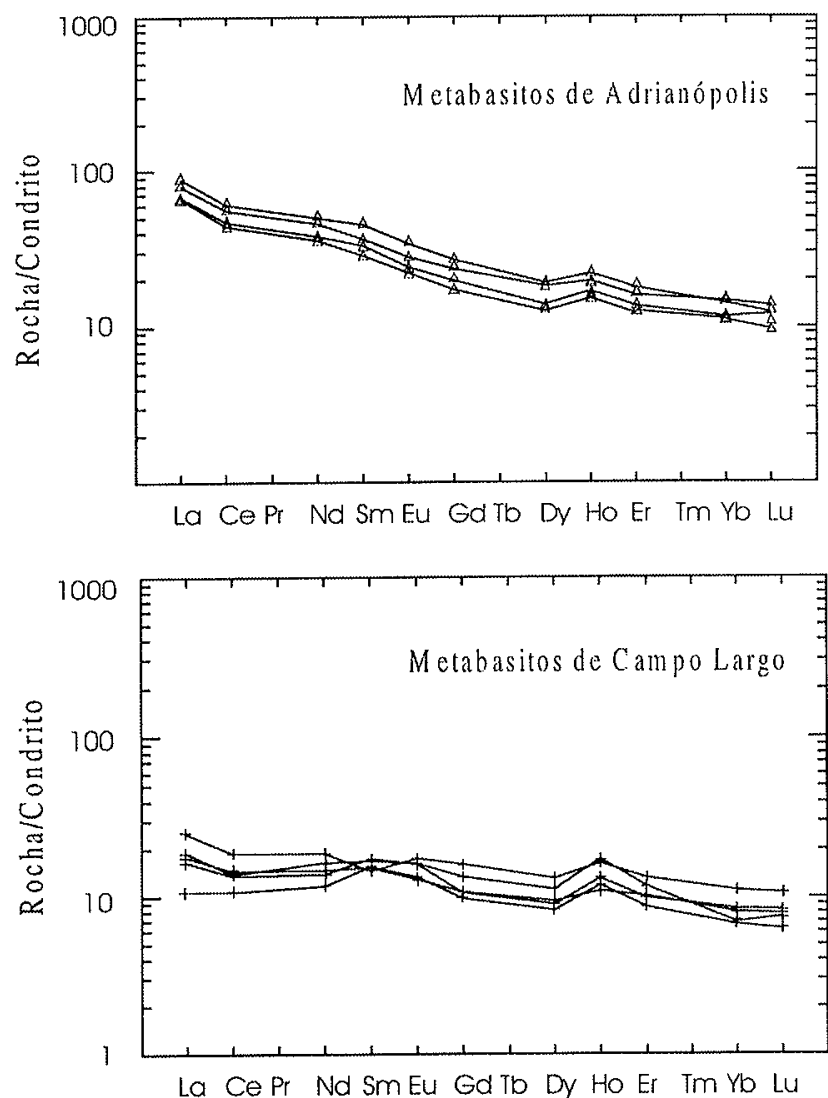

Figura 14 - Padrões de abundância dos elementos terras raras normalizados pelo condrito (Evensen et al. 1978) dos metabasitos de Adrianópolis e Campo Largo. 
basaltos de arcos. Por outro lado, vários outros estudos (e.g. Pineau et al. 1976, Hawkesworth et al. 1977, Saunders \& Tarney 1979) consideram que os basaltos de bacias de retro arco formam-se por fusão parcial do manto em processos semelhantes àqueles envolvidos na geração de basaltos normais ou enriquecidos de cadeias meso oceânicas.

As rochas precursoras dos metabasitos das regiões de Adrianópolis e Campo Largo podem ter tido esse ambiente de formação. No entanto, as características geoquímicas de basaltos toleiíticos do tipo $\mathrm{T}$ MORB (Campo Largo) e E-MORB tendendo para basaltos de ilhas oceânicas (Adrianópolis), não confirmam a formação de assoalho oceânico relacionado a abertura das bacias Setuva (Campo Largo) e Açungui (Adrianópolis), uma vez que essas rochas não apresentam evidências geológicas e geoquímicas para serem consideradas como parte de sequiências ofiolíticas.

Agradecimentos À FAPESP pelo apoio financeiro (processos 90/3948-1 e 91/0643-8) e a dois revisores anônimos da RBG pelas sugestões e críticas ao manuscrito.

\section{Referências}

Andrade e Silva A.C.G. 1990. A jazida de barita de Água Clara no âmbito do Precambriano do Vale do Ribeira, Estado do Paraná. Inst. de Geociências, Universidade de São Paulo, São Paulo, Tese de Doutoramento, 204p.

Andrade F.R.D., Nogueira Filho J., Popini M.U.F. 1990. Relatónio do mapa geológico do regiäo de Pantaninho - Morro Felpudo/PR. Relatório de graduação (inédito). Departamento de Geologia/UFPR, Curitiba/PR.

Beswick A.E. \& Soucie G. 1978. A correction procedure for metasomatism in an archean greenstone belt. Precamb. Res., 6:235-248.

Campanha G.A.C. 1991. Tectônica proterozóica no Alto e Médio Vale do Ribeira, Estados de São Paulo e Paraná. Inst. de Geociências, Universidade de São Paulo, São Paulo, Tese de Doutoramento, 296p.

Crawford A., Beccaluva J.L., Serri G. 1981. Tectonomagmatic evolution of the West Philippine-Mariana regions and the origin of boninites. Earth Planet. Sci. Letters, 54:346-356.

Daitx E.C. 1996. Origem e evolucão dos dopósitos sulfetados tipo-Perau $(P b-Z n-A g)$, com base nas jazidas Canoas e Perau (Vale do Ribeira, PR). Instit. de Geociências e Ciências Exatas, Universidade Estadual Paulista, Rio Claro, Tese de Doutoramento, $453 \mathrm{p}$.

Daitx E.C., Takahashi A.T., Ferreira J.C.G., Silva C.R., Maeyama O. 1983. Projeto Ant gorda, fase III. Mapeamento Geológico da área norte. DNPM/CPRM, São Paulo, $123 \mathrm{p}$

De La Roche H., Leterrier J., Grandclaude P., Marchal M. 1980. A classification of volcanic and plutonic rocks using RI-R2 diagram and major element analyses. It relationships with current nomenclature. Chemical Geology, 29:183-210.

Ebert H.D. 1987. Perrographische und tektonische Untersuchungen in der Serra do Cadeado - Autwölbung in Se-Paraná, Brasilien. Universität Clausthal, Clausthal, Tese de Doutoramento, $257 \mathrm{p}$.

Evensen N.M. Hamilton P.J., O'nions R.K. 1978 Rare earth abundances in chondritic meteorites. Geochimica et Cosmochimica Acta. 42:1199-1212.

Fiori A.P. 1985. Estudos geolósicos integrados do Pré-Cambriano paranaense. Convênio UFPR/MINEROPAR, tex to final, Curitiba/PR, inédito, 192p.

Fiori A.P. 1987. Aspectos estruturais e estratigráficos do Grupo Acungui e Formação Itaiacoca no Estado do Paraná. Convênio UFPR/MINEROPAR, texto final Curitiba/PR, inédito, $191 \mathrm{p}$.

Fiori A.P. 1990. Tectônica e estratigrafía do Grupo Açungui a norte de Curitiba. Inst de Geociências, Universidade de São Paulo, São Paulo, Tese de Livre Docência, 261p.

Fiori A.P. 1993. O Sistema de Cavalgamento Açungui (PR). Geociências, São Paulo, 12:187-208.

Frascá M.H.B.O., Figueiredo M.C.H., Almeida M.A., Coutinho J.M.V. 1990. Petrografia e Geoquímica da Formação Água Clara - Região de Araçaíba, SP. Boletim do IG-USP Série Científica, 21:73-92

Fritzsons Júnior O., Piekarz G.F., Falcade D. 1982. Geologia e potencial econômico do Grupo Setuva/PR. In: SBG, Congresso Brasileiro de Geologia, 32, Salvador, Ancis. 3:987*1001

Hasui Y Carneiro C D. R, Coimbra A.M. 1975. The Ribeira Folded Belt. Revista Brasileira de Geociências, 5:247-266.

Hasui Y Carneiro C.D.R. Bistrichi C.A. 1980. Estruturas e tectônica do Pré-Cambriano de São Paulo e Paraná. Anais da Acad. Brasileira de Ciênciass, 52:6]-76.

Hasui Y Ebert H.D Quade H. 1984. Aspectos geológicos da Megantiforma da Serra do Cadeado, PR. In: SBG, Congresso Brasileiro de Geologia, 33, Rio de Janeiro, Anais, 7:2380-2394

Hawkesworth C.J., O'Nions R.K., Pankhurst P.J., Hamilton P.J., Evensen N.M. 1977. A geochemical study of island arc and back arc tholeiites from the Sotia Sea. Earth Planet. Sci. Letters, 36:253-262.

Irvine T.N. \& Baragar W.R.A. 1971. A guide to the chemical classification of the common volcanic rocks. Can. Jour: Earth Sci., 8:523-548.

Jarrard R.D. 1986. Relations among subduction parameters. Geophysical, 24:217-284.

Jensen L.S. 1976. A new cation plot for classifying subalkaline volcanic rocks. Ontatio Division of Mines, Misc., Paper 66.

JICA/MMAJ. 1981. Report on geological survey of Anta Gorda, Brazil: Phase I - Japan International Cooperation Agency. Relatório CPRM/DNPM, 79p.

JICA/MMAJ. 1982. On geological survey of Anta Gorda Phase II, Brazil - Japan International Cooperation Agency. Relatório CPRM/DNPM, $119 \mathrm{p}$.

JICA/MMAJ. 1983. Report on geological survey of Anta Gorda, Brazil: Phase I- Japan International Cooperation Agency. Relatório CPRM/DNPM, 11 1p.

IICA/MMAJ. 1984. Report on geological survey of Anta Gorda, Brazil - Japan International Cooperation Agency. Relatório CPRM/DNPM, 73p.
Katbeh A., Paludo M.A., Osama M.A. 1990. Relatório do mapa geológico da região de Povinho de São João/PR. Relatório de graduação (inédito). Departamento de Geologia/UFPR, Curitiba/PR

Leake B.E. 1964. The chemical distinction of between ortho- and para amphibolites. Jou : Petrol., 5:238-254.

Maniesi V. 1997. Petrologia das rochas anfibolíticas das regiñes de Adrianópolis, Campo Largo e Rio Branco do Sull/PR. Instit. de Geociências e Ciências Exatas, Universidade Estadual Paulista, Rio Claro, Tese de Doutoramento, 215p

Maniesi V., Oliveira M.A.F, Zanardo A. 1996. Quinismo mineral de anfibólios e sua relação com feições texturais nos corpos anfibolíticos de Adrianópolis e Campo Largo/ PR. In: SBG, Congresso Brasileiro de Geologia, 39, Salvador, Anatis, 6:138-140. MINEROPAR. 1986. Projeto Canha - Carumbé. Mapa geológico, escala 1:25.000

Miyashiro A. 1975. Classification, characteristics and origin of ophiolites. Jour: Geol., 83:249-281.

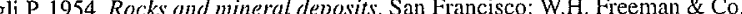

Pearce J.A. 1976. Statistical analysis of major element patterns in basalts. Jour. Petrol. 17:15-43.

Pearce J.A. 1983. Role of the sub-continental lithosphere in magma genesis at active continental margins. In: CJ Hawkesworth and MJ Norry (ed.) Continental basalss and mantle xenoliths. Shiva Nantwich, 230-249.

Pearce T.H. Gorman B.E., Birkett T.C. 1975. The TiO - $\mathrm{K}_{2} \mathrm{O}-\mathrm{P}_{2} \mathrm{O}_{5}$ diagram - a method of discriminating between oceanic and non-oceanic basalts ${ }^{2}$ Eurth Planet. Sci Letters, $24: 419-426$.

Piekarz G.F. 1981. Reconhecimento das unidades correlacionáveis à sequêencia mineralizada do Perau, Estado do Paraná. In: SBG, Simpósio Sul Brasileiro de Geologia, 3 Curitiba, Anais, 1:148-154.

Piekarz G.F. 1992. O Granito Passa Três/PR e as mineralizaçōes auriferas associadas. Universidade de Campinas, Campinas, Dissertação de Mestrado, 221 p.

Pineau, F. Javoy M., Hawkins W., Craing H. 1976. Oxygen isotope variation in marginal basin and ocean ridge basalts. Earth Planer. Sci. Letters, 28:299-307.

Pontes J.B. 1982. Geologia e potencialidade econômica da Formação Agua Clara (PR). In SBG, Congresso Brasileiro de Geologia, 32, Salvador, Anais, 1:1002-1016.

Reis Neto J.M. 1994. Faixa Itaiacoca: registro de uma colisäo entre dois blocos continentais no Neoproferozóico. Inst. de Geociências, Universidade de São Paulo, São Paulo, Tese de Doutoramento, 255p.

Reis Neto J.M \& Soares P.C. 1987 . Um estudo de caracterizacão termo-dinâmica de microestruturas dos grupos Açungui e Setuva (PR). In: SBG, Simpósio Sul Brasileiro de Geolog 3 Curitiba, Anais, 1:147-165.

Saunders AD \& Tarner J. 1979. The Geochemistry of basalts from a back-arc spreading center in the East Scotia Sea. Geoch. Cosmoch. Acta, 43:555-572

Soares P.C. 1987 . Sequiências tectono-sedimentares e tectônica deformacional no centrooeste do Escudo Paranaense. In: SBG, Simpósio Sul Brasileiro de Geologia, 3 , Curitiba, Anais, 2:743-772.

Soares P.C. 1988. Tectônica colisional em torno do Bloco Paraná, Brasil. In: SBG, Congresso Latino Americano de Geologia, Belém, Antis, 1:63-81.

Soares P.C. \& Góis J.R. 1987. Geologia do Granito Passa Três/PR e suas mineralizaçōes auriferas. In: SBG, Simpósio Sul Brasileiro de Geologia, 3, Curitiba, Anais, 2:487514

Sun S.S. 1980 Lead isotopic study of young volcanic rocks from mid-ocean ridges, ocean islands and islands arcs. Phil Trans. R. Soc. Lond. A297, 409-445.

Taylor B. \& Karner G.D. 1983. On the evolution of marginal basins. Geophrsical, 21:1727. 1741

Viljoen M.J, Viljoen R.P. Pearton T.N. 1982. The nature and distribution of Archean komatiite volcanics in South Africa. In: George Allen and Unwin, Komatiites, London, 51-79.

Winchester J A , Park R.G., Holland J.G. 1980. The geochemistry of Lewisian semipelitic schists from the Gairloch District, Wester Ross. Scott Jout: Geol., 16:165-179.

Yoder H.S. \& Tilley C.E. 1962. Origin of basalts magmas: an experimental study of natural and synthetic rock systems. Jour. Petrol., 3:342-532.

Manuscrito A-1084 Recebido em 5 de abril de 1999 Revisão dos autores em 6 de fevereiro de 2000 Revisão accita em 10 de feverciro de 2000 